\title{
COMPARISON OF LATERAL INTERNAL SPHINCTEROTOMY AND CONTROLLED INTERMITTENT ANAL DILATATION IN THE TREATMENT OF CHRONIC ANAL FISSURES: A PROSPECTIVE, RANDOMISED STUDY
}

\author{
Mervyn Correia ${ }^{1}$, Pandarinath Audi², Francis Pantaliao Noronha ${ }^{3}$ \\ ${ }^{1}$ Associate Professor, Department of Surgery, Goa Medical College, Bambolim, Goa. \\ ${ }^{2}$ Lecturer, Department of Surgery, Goa Medical College, Bambolim, Goa. \\ 3Professor, Department of Surgery, Goa Medical College, Bambolim, Goa.
}

\section{ABSTRACT}

\section{AIMS AND OBJECTIVE}

The main aim of this study was to assess the relief of symptoms and the healing of the anal fissure using the two techniques of lateral internal sphincterotomy and controlled intermittent anal dilatation.

\section{MATERIALS AND METHODS}

Thirty patients who were randomised into two groups underwent lateral internal sphincterotomy or controlled intermittent anal dilatation. Randomisation to treatment by either lateral internal sphincterotomy or controlled intermittent anal dilatation was done on the basis whether the patient's registration number was odd or even. A total of 16 patients were treated by lateral internal sphincterotomy and 14 patients by controlled intermittent anal dilatation. All cases were done under general anaesthesia. The improvement in patient's symptoms as well as healing of the fissure were recorded and the results were compared. No serious complications were observed in either group. Patients were followed up for six months post procedure.

\section{RESULTS}

No differences were observed with respect to immediate relief of pain, bleeding, mucous discharge, healing of the anal fissure, surgical complications and time off work. The post-operative symptoms in the form of pain, bleeding and constipation did not differ significantly between the two groups and were easily controlled with analgesic, stool softeners and sitz baths. The patients were also asked to hydrate themselves well and advised to have a diet rich in vegetables and fruit. Two months post-operatively, 16 patients in the lateral sphincterotomy group and 14 patients in the controlled intermittent anal dilatation group had healed completely and had no anal incontinence or other serious complications. At 6 months follow-up however 2 patients in the anal dilatation group complained of impaired control of flatus and faeces, although there was no soiling of the underwear. At the same point in time, one patient in the sphincterotomy group and 3 patients in the anal dilatation group had a recurrence. No statistical difference however existed in either treatment groups as regards to the relief of symptoms, the healing of the fissure and anal incontinence.

\section{CONCLUSION}

Lateral internal sphincterotomy is one of the most favoured procedures. The reason for this is the simplicity of the procedure, the minimal anaesthesia requirements and excellent results. Controlled intermittent anal dilatation applied with a standardised technique reduced anal canal resting pressure, cured symptoms and provided symptomatic healing that was equivalent to that of a lateral internal sphincterotomy. Since there were no findings of incontinence or situations which resulted in anal sphincter damage, we conclude that controlled intermittent anal dilatation is suitable for patients with chronic anal fissures because of its less invasive nature as compared to lateral sphincterotomy with equivalent efficacy and safety. In addition, the controlled intermittent anal dilatation method may be an alternative procedure in older and multiparous women who has a higher risk of incontinence.

\section{KEYWORDS}

Anal Fissure, Incontinence, Anal Dilatation, Lateral Internal Sphincterotomy.

HOW TO CITE THIS ARTICLE: Correia M, Audi P, Noronha FP. Comparison of lateral internal sphincterotomy and controlled intermittent anal dilatation in the treatment of chronic anal fissures: a prospective, randomised study. J. Evolution Med. Dent. Sci. 2016;5(68):4901-4904, DOI: 10.14260/jemds/2016/1114

\section{INTRODUCTION}

An anal fissure also called fissure-in-ano is a very painful condition that is frequently neglected and very often incorrectly treated. It is a longitudinal split in the anoderm of the distal anal canal, which extends proximally towards but

Financial or Other, Competing Interest: None.

Submission 16-07-2016, Peer Review 10-08-2016,

Acceptance 16-08-2016, Published 25-08-2016.

Corresponding Author:

Mervyn Correia,

Resicom Elite

Flat C-02 of Kadamba Depot Road,

Alto-Porvorim,

Bardez-403521, Goa.

E-mail: mcorreia@bsnl.in

DOI: $10.14260 /$ jemds/2016/1114 not beyond the dentate line. It is usually located in the posterior commissure in the midline, probably because of the relatively unsupported nature and poor perfusion of the anal wall in that location. More than $90 \%$ of fissures are acute and resolve spontaneously. Chronic fissures are those that have failed to heal after six weeks of conservative treatment and usually require pharmacological or surgical intervention. Patients with anal fissures present with pain, bleeding during defecation, mucous discharge and constipation and fissures in ano are one of the most common medical conditions encountered in proctology.(1)

Our study compared lateral internal sphincterotomy and controlled intermittent anal dilatation, and found the results of symptom relief and fissure healing and complications to be comparable. 


\section{MATERIALS AND METHODS}

\section{Study Design}

This was a single centre prospective study conducted by Department of Surgery, Goa Medical College. The patients were selected from those attending the outpatient department as well as the emergency department of the college hospital. A total of 30 patients between the ages of 12 and 80 with chronic anal fissure were included in the study between October 2014 and September 2015. The protocol was approved by Ethical Committee of the Institution, written informed consent was obtained from all participants. Patients having inflammatory bowel disease, AIDS, tuberculosis, sexually transmitted diseases or medically related conditions like pregnancy were excluded from the study.

\section{Inclusion Criteria}

Patients between the ages of 12 and 80, having chronic anal fissure.

\section{Exclusion Criteria}

Patients less than 12 and more than 80 years were excluded from the study.

Patients having inflammatory bowel disease, AIDS, tuberculosis, sexually transmitted diseases or medically related conditions like pregnancy were excluded from the study.

\section{METHODS}

All subjects satisfying the criteria were carefully worked up in terms of detailed history and clinical examination. Laboratory investigation included complete haemogram, urine routine examination and FBSL. A chest X-ray and ECG were done when required.

Patients were asked to fill out a questionnaire that detailed their symptoms. Anal pain was assessed before beginning treatment and at follow-up visits using a linear visual analog pain score. Rectal bleeding, mucous discharge and constipation were assessed at the beginning and at the end of treatment. Anal incontinence was assessed by means of a validated scoring and grading system as described by Pescatori et al.(2)

\section{Lateral Internal Sphincterotomy Group}

Under general anaesthesia with the patient in the lithotomy position, a lateral internal sphincterotomy using the open method was used. An incision was made across the intersphincteric groove, separating the internal sphincter from the anal mucosa by blunt dissection up to the dentate line and dividing the internal sphincter using scissors. The surgical procedures were all carried out in the same surgical unit enabling uniformity to be maintained. The patients were discharged from the hospital the next day with analgesics, sitz baths and stool softeners, and advised to report immediately in case of any eventuality. After two months, scar healing was assessed and improvement in symptoms and complications if any were recorded. Patients were reviewed again at six months, especially to look for fissure recurrence and anal incontinence.

\section{Controlled-Intermittent Anal Dilatation Group}

Under general anaesthesia, the bivalved anal speculum which is capable of being adjusted for anal stretch was placed in the anal canal. The anal speculum was gradually opened to enable an anal dilatation of a diameter of $4 \mathrm{~cm}$. This was then gradually relaxed in 20 seconds. The dilation-relaxation sequence was repeated 10 times during a 3 min period. We performed this intermittent procedure to avoid ischaemic and uncontrolled traumatic sphincter rupture that results from Lord's procedure. Again to maintain uniformity, the surgeons from the same surgical unit participated in the procedure. The patients were discharged from the hospital the next day with analgesics, sitz baths, stool softeners and advised to report immediately in case of any eventuality. After two months, scar healing was assessed and improvement in symptoms and complications were recorded. Patients were reviewed again at six months, especially to look for fissure recurrence and anal incontinence.

\section{RESULTS}

No differences were observed with respect to immediate relief of pain, bleeding, mucous discharge, healing of the anal fissure, surgical complications and time off work.

In both the groups as seen from both table 1 and 2, recovery was quick and patients were off to work within seven days. Table 3 shows the recurrence and anal incontinence rate. There was only one recurrence in the sphincterotomy group at $6.25 \%$ as compared to three in the anal dilatation group $21.4 \%$. The patients are being treated conservatively for the time being, although surgery has been offered to them.

Two patients had impaired control of flatus and feces at $14.3 \%$ in the anal dilatation group. This minor complication was treated with toilet training and perineal exercises. The patients have shown tremendous improvement and are still following up in the outpatient department.

There was no anal incontinence in the sphincterotomy group.

There was no statistical significance to both these major complications.

\begin{tabular}{|c|c|c|}
\hline & LIS & CIAD \\
\hline Number of patients & 16 & 14 \\
\hline Male:Female ratio & $9: 7$ & $7: 7$ \\
\hline Median age in years (range) & $\begin{array}{c}39 \\
(12-76)\end{array}$ & $\begin{array}{c}34 \\
(18-80)\end{array}$ \\
\hline $\begin{array}{c}\text { Duration of symptoms in } \\
\text { months }\end{array}$ & $6-24$ & $4-28$ \\
\hline Follow-up time in months & 6 & 6 \\
\hline Time off work in days & 7 & 3 \\
\hline \multicolumn{3}{|c|}{$\begin{array}{l}\text { Table 1: Comparability of Patients Treated by Lateral } \\
\text { Internal Sphincterotomy (LIS) and Controlled } \\
\text { Intermittent Anal Dilatation (CIAD) }\end{array}$} \\
\hline
\end{tabular}

\begin{tabular}{|c|c|c|c|c|}
\hline Symptom & Time & LIS (n=16) & CIAD (n=14) & P-value \\
\hline \multirow{2}{*}{ Pain } & Pre-operative & 16 & 14 & \multirow{2}{*}{ NS* } \\
\hline & Post-operative & 1 & 5 & \\
\hline \multirow{2}{*}{ Bleeding } & Pre-operative & 15 & 13 & \multirow{2}{*}{ NS* } \\
\hline & Post-operative & 1 & 2 & \\
\hline \multirow{2}{*}{ Discharge } & Pre-operative & 16 & 14 & \multirow{2}{*}{ NS* } \\
\hline & Post-operative & 5 & 5 & \\
\hline Fissure & $\begin{array}{l}\text { Pre-operative } \\
\text { Post-operative }\end{array}$ & $\begin{array}{c}16 \\
1\end{array}$ & $\begin{array}{c}14 \\
3\end{array}$ & NS* \\
\hline & vement in Symp & g of Fis. & Groups and & \\
\hline
\end{tabular}

*Fisher exact test. NS= not significant. 


\begin{tabular}{|c|c|c|c|c|}
\hline \multicolumn{2}{|l|}{} & \multicolumn{2}{c|}{$\begin{array}{c}\text { Impaired } \\
\text { Control } \\
\text { of }\end{array}$} & \\
\hline & Recurrence & Flatus & Feces & $\begin{array}{c}\text { Fecal } \\
\text { Soiling of } \\
\text { Underwear }\end{array}$ \\
\hline $\begin{array}{c}\text { LIS } \\
(\mathrm{n}=16)\end{array}$ & 1 & 0 & 0 & 0 \\
\hline $\begin{array}{c}\text { CIAD } \\
(\mathrm{n}=14)\end{array}$ & 3 & 2 & 2 & 0 \\
\hline $\begin{array}{c}\text { P- } \\
\text { value }\end{array}$ & NS* & NS* & NS* \\
\hline $\begin{array}{c}\text { Table 3: Functional Results of Lateral Internal } \\
\text { Sphincterotomy (LIS) and Controlled Intermittent Anal } \\
\text { Dilatation (CIAD) }\end{array}$ \\
\hline \multicolumn{4}{|c|}{} \\
\hline
\end{tabular}

*Fisher exact test. NS= not significant.

\section{DISCUSSION}

An anal fissure is a linear ulcer in the lower half of the anal canal, usually located in the posterior commissure in the midline. The majority of these will self-heal; however, some become deep and chronic and will not heal. The spasm of the internal sphincter is a well-accepted cause and occurs as a result of the trauma caused by the passage of a hard, scybalous and sometimes large and bulky stool which develops secondary to constipation.

When fissures are found laterally, tuberculosis, occult abscesses, leukemic infiltrates, carcinoma, Acquired Immunodeficiency Syndrome (AIDS) or inflammatory bowel disease should be considered as potential causes.(3) Sexually transmitted infections that may affect the anorectal area are syphilis, herpes, chlamydia and human papilloma virus.

It is well-accepted that ischaemic events are effective in poor healing and recurrence of anal fissures.(4) Blood supply to the anoderm at the posterior midline is significantly less. The reduced blood supply to the lesion is indicated by the absence of granulation tissue at the base of the fissure and a very slow growth of the anoderm even when the traditional conservative treatment eases the trauma due to hard stool.(5) Studies have shown higher than normal resting anal canal pressures and reduced anal blood flow in the posterior midline. It is therefore believed that anal fissures are the result of anal sphincter hypertonia and subsequent mucosal ischaemia.(4)(6)

The most common symptoms in our patients were pain $100 \%$, bleeding 93\%, anal mucous discharge $100 \%$ and constipation $73 \%$.

Surgery may be recommended if other treatment modalities have not worked. Surgical procedures are generally reserved for people with anal fissure who have tried medical therapy for at least one to three months and have not healed. It is not the first option in treatment. It is generally considered to be the most effective treatment for anal fissures with more than $90 \%$ of people experiencing good long-term results. However, it does carry a small risk of complications. In the patients with anal fissure, effective medical treatment, anal dilatation and lateral internal sphincterotomy decreases the anal canal resting pressure and helps to treat the pain. The decrease in the anal canal pressure and the cessation of pain after the effective treatment supported the ischaemic theory of Gibbons and the increase in anal sphincter tone has become a cause rather than the result of an anal fissure.(6)(7)

Division of internal sphincter fibres to relieve the sphincter spasm is presently considered the preferred therapy for chronic, recurrent and non-healing fissures.(8) Lateral internal sphincterotomy is the preferred method of surgery for persons with chronic anal fissures and is generally used when medical therapy has failed.( 9 )

The procedure has been shown to be very effective with $96 \%$ of fissures healing at a median of 3 weeks in one trial.(10) It is associated with a lower rate of side effects than older techniques, such as posterior internal sphincterotomy and anoplasty.(10) It has also been shown to be superior to topical Glyceryl Trinitrate (GTN 0.2\% ointment) in long-term healing of fissures with no difference in fecal continence.(11) The pain from the sphincterotomy is usually mild and is often less than the pain of the fissure itself. Patients often return to normal activity within one week. Excellent results have been reported by Arroyo et al with healing rates of $93-100 \%$ and negligible incontinence.(12) Minor fecal incontinence and difficulty controlling flatulence are common side effects following surgery.(13) Persistent minor fecal incontinence has been reported in $1.2 \%$ to $3.5 \%$ of patients; however, this does not appear to be significantly different to the rate of minor fecal incontinence experienced by patients treated with topical GTN.(9)

However, in a systematic review carried out by Garg P et al to analyse continence at 2 years or more after lateral internal sphincterotomy for chronic anal fissure, the long term risk of anal incontinence after lateral internal sphincterotomy was found to be quite significant.(14) He had 324 studies screened, $22(\mathrm{n}=4512)$ were included in the study and he reported an overall continence disturbance rate was $14 \%$. Most other studies however do not report such high figures.

Stretching of anal sphincter, the traditional Lord's anal dilatation was described by Recamier in 1838. This was one of the most favoured and accepted methods of treating the anal fissures.(15) The main reason of attraction to the procedure is its extreme simplicity. Since almost no instruments are needed for this procedure, it could be performed at the primary health centres or inadequately equipped hospitals situated at small townships.(5) In the early 1990s, however, being a repeatable method anal dilation proved to be very effective and showed a very low incidence of side effects. Since then at least one controlled, randomised study has shown there to be a little difference in healing rates and complications between controlled anal dilation and lateral internal sphincterotomy,(7) while another has again shown high success rates with anal dilation coupled with low incidence of side effects.(16) The results of anal dilatation using a bivalve anoscope, also called as endoscopic dilatation are comparable with those of lateral sphincterotomy and can be achieved at a lower complication rate with only minor and temporary complications and performed by physicians with no specific surgical training.(17)

In our study, there was no significant difference between lateral internal sphincterotomy and controlled intermittent anal dilatation as far as improvement in patient symptomology and complications were concerned. Our results were similar to the study conducted by Yucel $\mathrm{T}$ et al. The manner in which the anal dilatation was done by us was more or less similar to the one conducted in their study. If the anal dilatation is done in an intermittent and controlled manner, and if a standardised technique is used, the resting anal pressures will reduce providing good symptomatic relief to the patient as well as having a negligible anal incontinence rate with results equivalent if not better than lateral internal sphincterotomy. 


\section{REFERENCES}

1. Arroyo A, Perez F, Serrano P, et al. Surgical versus chemical (botulinum toxin) sphincterotomy for chronic anal fissure: long-term results of a prospective randomized clinical and manometric study. Am J Surg 2005;189(4):429-34.

2. Pescatori $\mathrm{M}$, Anastasio $\mathrm{G}$, Bottini $\mathrm{C}$, et al. New grading and scoring for anal incontinence: evaluation of 335 patients. Dis Colon Rectum 1992;35(5):482-7.

3. Pfenninger JL, Zainea GG. Common anorectal conditions: part II. Lesions. Am Fam Physician 2001;64(1):77-88.

4. Gupta PJ. Internal anal sphincterolysis for chronic anal fissure: a prospective, clinical and manometric study. Am J Surg 2007;194(1):13-6.

5. Gupta PJ. Treatment of fissure-in-ano revisited. Afr Health Sci 2004;4(1):58-62.

6. Gibbons CP, Read NW. Anal hypertonia in fissures: cause or effect? Br J Surg 1986;73(6):443-5.

7. Yucel T, Gonullu D, Oncu M, et al. Comparison of controlledintermittent anal dilatation and lateral internal sphincterotomy in the treatment of chronic anal fissures: a prospective, randomized study. International Journal of Surgery 2009;7(3):228-31.

8. Al-Raymoony AE. Surgical treatment of anal fissures under local anesthesia. Saudi Med J 2001;22(2):114-6.

9. Schubert MC, Sridhar S, Schade RR, et al. What every gastroenterologist needs to know about common anorectal disorders. World J Gastroenterol 2009;15(26): 3201-9.

10. Nyam DC, Pemberton JH. Long-term results of lateral internal sphincterotomy for chronic anal fissure with particular reference to incidence of fecal incontinence. Dis Colon Rectum 1999;42(10):1306-10.
11. Brown CJ, Dubreuil D, Santoro L, et al. Lateral internal sphincterotomy is superior to topical nitroglycerin for healing chronic anal fissure and does not compromise long-term fecal continence: six-year follow-up of a multicenter, randomized, controlled trial. Dis Colon Rectum 2007;50(4):442-8.

12. Arroyo A, Perez F, Serrano P, et al. Open versus closed lateral sphincterotomy performed as an outpatient procedure under local anesthesia for chronic anal fissure: prospective randomized study of clinical and manometric long-term results. J Am Coll Surg 2004;199(3):361-7.

13. Khubchandani IT, Reed JF. Sequelae of internal sphincterotomy for chronic fissure-in-ano. Br J Surg 1989;76(5):431-4.

14. Garg P, Garg M, Menon GR. Long-term continence disturbance after lateral internal sphincterotomy for chronic anal fissure: a systematic review and metaanalysis. Colorectal Dis 2013;15(3):e104-17.

15. Saad AM, Omer A. Surgical treatment of chronic fissure-inano: a prospective randomised study. East Afr Med J 1992;69(11):613-5.

16. Renzi A, Brusciano L, Pescatori M, et al. Pneumatic balloon dilatation for chronic anal fissure: a prospective, clinical, endosonographic and manometric study. Diseases of the Colon and Rectum 2005;48(1):121-6.

17. Pérez-Miranda M, Robledo $P$, Alcalde M, et al. Endoscopic anal dilatation for fissure-in-ano: a new outpatient treatment modality. Rev Esp Enferm Dig 1996;88(4):26572. 